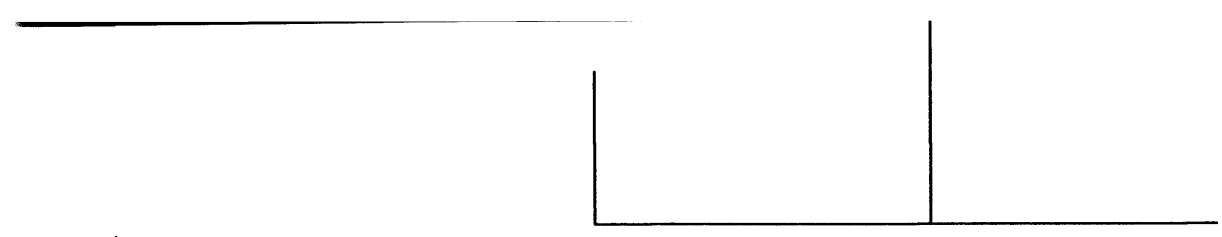

Rev. Latinoam. Psicopat. Fund., IX, 4, 750-758

Graham Shulman, "Reflections on Eugennio Gaddini's paper 'On Imitation'"

Maria Rhode, "Mirroring, imatation, identification: the sense of self in relation to the mother's internal world" Graham Music, "Surfacing the depths: thoughts on imitation, ressonance and growth"

Colwin Trevarthen, "First things first: infants make gook use of the sympathetic rythm of imitation, without reason or language" Journal of Child Psychoterapy, v. 31, 2005. Resenhado por: Ariana Lucero, Flavia Torquetti, Leonardo Poggiali, Lucas Carvalho Ribeiro e Paulo de Carvalho Ribeiro

\title{
Um lugar para a imitação em psicanálise
}

Os fenômenos de imitação raramente são tomados como objeto de estudo pelos psicanalistas. Sua vinculação à sugestão, à hipnose e aos efeitos imaginários considerados alienantes foi, certamente, um dos principais motivos deste aparente desinteresse pelo tema em questão. Ultimamente, no entanto, a necessidade de diálogo entre psicanalistas e demais estudiosos do psiquismo humano, principalmente os neocognitivistas, tem contribuído para que a imitação se imponha como tema de estudo, pelo menos entre psicanalistas comprometidos com o atendimento de crianças e/ou interessados nas teorias do desenvolvimento psíquico. É justamente esta tendência que pode ser confirmada pela publicação de um número recente do Journal of Child Psychoterapy (volume 31, de abril de 2005), vinculado à Association of Child Psychoterapy da Grã-Bretanha, contendo quatro importantes artigos sobre os fenômenos de imitação precoce. Além desses artigos, o número da revista em questão traz uma homenagem a Donald Meltzer, falecido em 


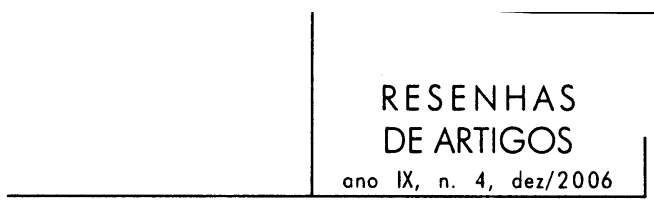

agosto de 2004; um artigo sobre o trabalho clínico com crianças adotadas e um relato de caso envolvendo abusos sexuais na infância. Focalizaremos aqui os artigos dedicados à imitação.

Primeiramerte, temos o artigo de Graham Shulman, "Reflections on Eugennio Gaddini's paper 'On Imitation'”, que revê e discute detalhadamente o texto pioneiro de Eugennio Gaddini (psicanalista italiano já falecido, discípulo de Eduardo Weiss), hoje considerado imprescindível para uma compreensão propriamente psicanalítica da imitação. Em seguida, um artigo de Maria Rhode "Mirroring, imitation, identification: the sense of self in relation to the mother's internal world" -, que aborda, a partir de sua experiência clínica com crianças autistas, os diferentes tipos de imitação, as relações entre imitação e identificação, além dos usos da imitação no desenvolvimento psíquico. Graham Music contribui com o artigo "Surfacing the depths: thoughts on imitation, ressonance and growth", no qual descreve seu trabalho com uma criança autista, em que manifestações imitativas e de espelhamento (mirroring) desempenharam papel fundamental no aparecimento de expressões emocionais. Music articula seus achados clínicos não só com a teoria psicanalítica, mas também com descobertas das neurociências, tais como os "neurônios espelho". Por fim, Colwin Trevarthen, psicólogo do desenvolvimento de orientação cognitivista, questiona e debate em seu trabalho "First things first: infants make good use of the sympathetic rythm of imitation, without reason or language”, as razões que levam tanto psicanalistas quanto psicólogos do desenvolvimento a encontrarem grande dificuldade em reconhecer a importância das atividades de imitação em neonatos. Trevarthen lança mão de conceitos e teorias das neurociências para propor uma mudança neste quadro.

Antes de expormos mais detidamente as principais idéias e formulações acerca da imitação presentes nos artigos acima mencionados, julgamos necessário assinalar que algumas concepções e usos da teoria psicanalítica adotados pelos autores em questão possuem uma nítida filiação teórica à escola inglesa de psicanálise, principalmente a Melanie Klein. Percebe-se, ainda, a influência da neurociência da cognição, marcadamente dos experimentos de Donald Meltzoff, mencionados não só no artigo de Trevarthen, que não é psicanalista, mas também nos textos dos autores psicanalistas. Essa mistura de referenciais teóricos favorece o aparecimento do que consideramos equívocos nas formulações sobre o funcionamento psíquico em geral, e sobre a imitação em particular. Por exemplo, pode-se observar uma tendência ao inatismo na concepção de funcionamento do aparelho psíquico, tendência essa que acaba por conduzir a uma interpretação acentuadamente biologizante do pensamento freudiano, fazendo com que o papel do outro perca importância, em benefício de uma visão do bebê como detentor, desde muito precocemente, de recursos cognitivos e perceptivos que lhe 


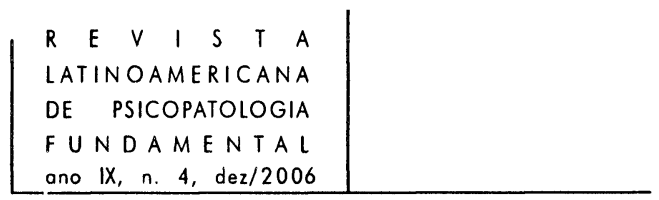

assegurariam uma posição de atividade e iniciativa muito superior àquela que julgamos real.

Feitas estas observações, passemos, então, às considerações sobre os artigos em questão. Não nos deteremos no artigo de Shulman, que resume e discute as principais idéias de Gaddini sobre imitação precoce. Devido à importância dos textos de Gaddini, julgamos que o artigo de Shulman requer uma resenha à parte.

No artigo intitulado "Mirroring, imitation, identification: the sense of self in relation to mother's internal world", Maria Rhode inicia suas considerações sobre imitação citando um estudo realizado por Kugiumutzakis (1998), no qual se comprova que os bebês imitam a protrusão da língua por estranhos até 45 minutos após o nascimento, ou seja, em um período no qual não se pode supor nenhuma influência da aprendizagem. Essa imitação muito precoce seria uma qualidade quase instintiva do ser humano a serviço do relacionamento. Assim, o adulto, ao mostrar a língua para a criança, se oferece como um parceiro de conversa que se expressa numa linguagem gestual, compreensível ao bebê. Entretanto, a qualidade da imitação evolui no curso do primeiro ano de vida, tanto em relação às ações que eliciam a imitação quanto em relação ao grau de intencionalidade com que os bebês observam o adulto que realiza uma ação e propositadamente perseveram no esforço de reproduzi-la.

Antes de prosseguir em suas considerações, Rhode destaca a "má fama" que a imitação sempre teve desde o surgimento da teoria psicanalítica. Segundo a autora, a imitação é muito mais freqüentemente discutida no âmbito do narcisismo, entendido como um estado anobjetal, do que em um contexto desenvolvimental. Desse modo, a imitação foi relegada ao segundo plano nos processos de internalização e assimilação de experiências que levam a um genuíno enriquecimento da personalidade.

Seguindo essa mesma linha de raciocínio, a autora argumenta também que a imitação neonatal com sua qualidade desenvolvimental e a imitação mútua, a serviço do que Trevarthen (1979) chamou intersubjetividade primária, não são reconhecidas como importantes na psicanálise. Exemplos destes casos são as situações $\mathrm{em}$ que mãe e bebê reproduzem as mesmas expressões, gestos e vocalizações um do outro, ou os reproduzem em outro modo sensório, como o bebê que move suas pernas e braços no ritmo da fala da mãe ou, ainda, a mãe que usa a sua voz para refletir o ritmo dos movimentos do bebê.

O tipo de imitação que Rhode considera importante é aquele em que uma reciprocidade cooperativa pode ser estabelecida entre mãe e bebê de modo que haja um favorecimento da comunicação e da sintonia. Para designar esta modalidade de imitação, a autora emprega o conceito de imitação desenvolvimental e defende sua proximidade com o conceito de identificação primária. Na imitação 


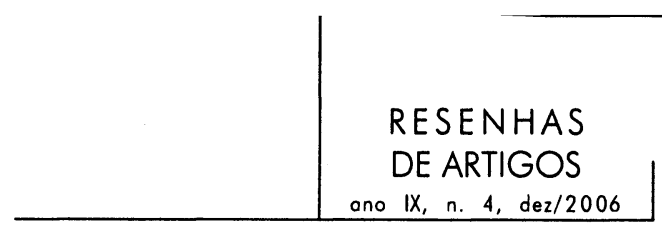

desenvolvimental, o bebê é experimentado e se experimenta como alguém como a mãe, sendo capaz de interagir com ela por combinações. A mãe e o bebê que trocam os ritmos, gestos, vocalizações e ações um com o outro, são ambos completos, e, por conseguinte, a relação entre eles é complementar e recíproca, mais do que competitiva. Este tipo de interação entre mãe e bebê favorece, segundo Rhode, os fenômenos de introjeção, possibilitando assim uma aproximação entre este tipo de imitação e a identificação projetiva.

Dando prosseguimento às suas idéias, Rhode cita uma pesquisa na qual crianças autistas respondem ao ser imitadas (Lee, 2004), mas, nestes casos, elas não estariam imitando sozinhas, de maneira natural, como as outras crianças fazem. Parece que falta algo na capacidade de identificação primária nessas crianças. Isso explicaria o fato de se considerar um dado clínico positivo a imitação que o autista começa a fazer de aspectos particulares e específicos, extraídos diretamente da relação com o terapeuta. Esta modalidade de imitação, que se diferencia daquelas encontradas no contexto da identificação adesiva ou projetiva, pode ajudar a clarear as condições que são necessárias para uma imitação que, no desenvolvimento normal, parece ser automática.

Uma dessas condições refere-se, segundo Rhode, a um tipo específico de olhar. O contato visual espelhado (mirroring) possibilitaria ao bebê o reconhecimento de um terceiro objeto na relação, os objetos internos da mãe. Rhode relaciona o terceiro objeto a condições edípicas que permitiriam a imitação desenvolvimental e a introjeção. É por meio da estruturação edípica pelo olhar, acima mencionada, que Maria Rhode destaca o equilíbrio entre a criança e os ocupantes internos da mãe como precondição para a identificação primária - que, como vimos, é a imitação de tipo desenvolvimental. Algumas vezes, as crianças que ainda não têm certeza da diferença entre introjetar algo de uma pessoa e destruí-la precisam restabelecer o contato visual com o outro para que consigam possuir e mostrar o que elas assimilaram dele.

Tal fato nos permite inferir que a posição equilibrada para uma identificação primária oferece condições para introjeção e assimilação fundadas no contato visual significativo entre um self e outro. Na contramão desse processo estariam as identificações que Rhode denomina de "narcísicas" - adesiva e projetiva -, que dificultariam a separação e a individuação.

Por fim, Rhode assinala que as fantasias do objeto interno são centrais para o senso de identidade, mas a capacidade da mãe de distinguir entre seu próprio objeto interno e seu bebê externo serve como apoio à capacidade do bebê de distinguir entre a mãe externa e seus objetos internos, e, conseqüentemente, entre introjetar aquilo que vem da mãe e danificá-la. Nessa situação, a criança não é bloqueada e há espaço para conteúdos emocionais. Criança e mãe podem, então, tornarem-se completas e se envolverem em relações recíprocas. A autora acredita 


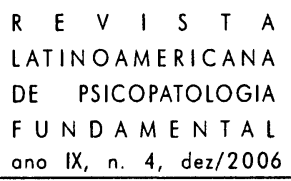

que esse contexto favoreceria o tipo particular de olhar que possibilitaria à criança autista começar a imitar o outro.

No segundo artigo da série sobre imitação, intitulado "Surfacing the depths: thoughts on imitation, resonance and growth", Graham Music procura mostrar a importância da imitação no desenvolvimento infantil, apoiando-se nas neurociências e em casos clínicos para destacar o papel dos comportamentos imitativos na promoção das relações intersubjetivas que são essenciais para a estruturação do psiquismo.

De acordo com Music, a psicanálise não vê a imitação como algo a ser valorizado no desenvolvimento, pois ela estaria associada com aparências, superficialidade, adoção de papéis que visariam o preenchimento de um vazio interno. Como exemplo disso ele cita o conceito de identificação adesiva formulado por E. Bick (1968, apud Music, 2005) e os escritos de Martha Harris (1975, apud Music, 2005). Uma colagem superficial aos objetos, no caso de Bick, e, no caso de Harris, uma imitação de características superficiais tomando o lugar da aprendizagem pela experiência são, segundo ele, descrições que distanciam a abordagem psicanalítica de uma percepção adequada dos fenômenos de imitação precoce.

As pesquisas de autores cognitivistas como Meltzoff, Kugiumutzakis e

754 Trevarthen são, segundo Music, base para se afirmar que a imitação precoce não é um simples reflexo neurológico, mas uma capacidade inata de estimular respostas ativamente, de provocar reações que o bebê espera encontrar em outras pessoas. Os bebês imitam gestos comunicativos, o que faz com que esse fenômeno seja essencial na aprendizagem social.

Fortalecendo sua hipótese de uma capacidade humana inata para a imitação, Music cita a descoberta dos neurônios-espelho pelos neurocientistas Rizzolati e Craighero. Fazendo pesquisas neurológicas em macacos, os pesquisadores descobriram que o mesmo grupo de neurônios que era acionado quando um deles efetuava uma ação determinada era também acionado em outro macaco que apenas observava o primeiro. Recentemente foi demonstrado que o mesmo acontece em humanos ao observarem o comportamento de outras pessoas. Esses neurônios-espelho confirmam o papel da imitação na aprendizagem e na comunicação. Eles mostram como é possível antecipar o encadeamento das ações de outras pessoas, assegurando assim uma base biológica para a intersubjetividade.

O caso de um paciente de 11 anos, que não parecia ter um senso de eu formado e não conseguia ficar sozinho, exemplifica a imitação no contexto clínico. Ele imitava a televisão e o terapeuta, palavra por palavra, mesmo não conseguindo articular uma só frase por si mesmo. Imitava também os gestos de outras pessoas quase que involuntariamente. Segundo Music, vários autores, como Tustin, 


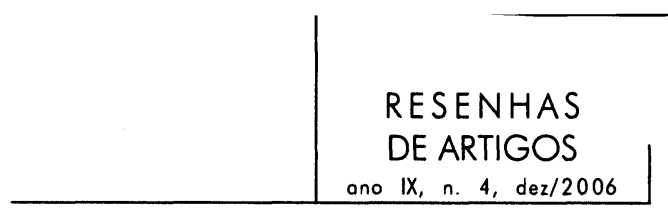

Gaddini, Weiss e Winnicott, descreveram fenômenos semelhantes como uma forma de defesa contra ansiedade.

$\mathrm{Na}$ opinião do autor, contudo, os processos imitativos não aparecem sempre como uma forma de defesa, mas têm também uma característica desenvolvimental importante. Eles são sinais de um desejo da criança de entrar no mundo das relações sociais a partir da busca de reprodução do que observa em outras pessoas. Music cita o caso de outro de seus pacientes, um garoto de seis anos, adútadjo, que raspou seu cabelo para ficar careca como o terapeuta, além de imitar trejeitos do pai. No início de sua vida ele não havia tido figuras constantes com as quais pudesse se identificar, e agora imitava características concretas do pai e do terapeuta. Essa imitação era diferente de uma forma saudável de identificação, mas mostrava um desejo de tornar-se como o outro.

Vemos, assim, que Music encara a imitação como uma abertura e um desejo de entender e ser entendido. Ele vê nesses gestos imitativos um potencial para comunicação, um tipo de interação "proto-social". Mais do que uma forma de defesa, a imitação é o solo sobre o qual o mundo psíquico da criança irá se desenvolver. Music acredita que o autismo poderia ter como causa uma falha no que ele chama de sistema de neurônios-espelho. Essa falha, ao impedir a criança autista de imitar, a impediria também de entrar no mundo social e intersubjetivo.

Music discute o caso de Carol, uma paciente de cinco anos que apresentava características autísticas. Ela não habitava o mundo simbólico, parecia não ter consciência de seu corpo e era extremamente ligada a rotinas. Além disso, apresentava hipersensibilidade a estímulos do ambiente e falava consigo mesma, sem tentativa de comuniraçã ši Carol, que não era primogênita, nascera em uma época particularmente difícil para a família. Com estes dados em mãos Music formula a hipótese de que Carol teria se tornado autista em decorrência de uma dificuldade constitucional de imitar, somada a uma presença insuficiente dos pais logo após seu nascimento.

No início do tratamento Music se preocupou em tentar compreender, descrever e imitar o que se passava no mundo de Carol. Durante as sessões ele descrevia em voz alta o que a menina fazia, exagerando também em voz alta qualquer emoção que sentisse surgir nela. Em outros momentos ele imitava atos da menina ou frases por ela ditas. Essa abordagem resultou em respostas positivas dadas por Carol, que reagia às imitações de forma interativa, como não fazia antes do início do tratamento. A hipótese de Music é a de que, ao se ver imitada, Carol experienciou seus sentimentos de forma objetiva, vendo seu eu de forma um pouco mais real.

Music usa o conceito de objeto transformacional, de Bollas, para refletir sobre a melhora de Carol. Seu papel teria sido o de potencializar o surgimento de uma subjetividade em Carol. Para isso, o terapeuta usou, além da imitação, a 


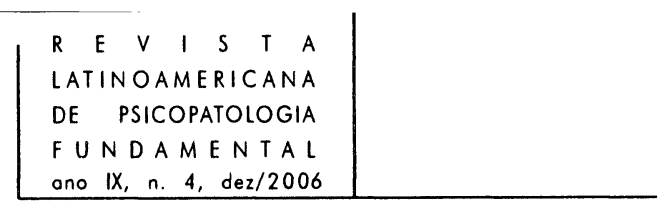

técnica que ele chama de marking, na qual as falas da criança são repetidas, exagerando-se o sentimento que a criança parece ter no momento. Além de exagerar um afeto, o ato de marcar também deve dar ênfase ao que não está claramente visível, mas que existe em potencial. Music chama atenção para o fato de que se deve escolher aqueles comportamentos que geram confiança e comunicação, evitando assim cometer o erro de marcar sentimentos que não geram superação de barreiras.

Por fim, podemos sublinhar que Music procura nas ciências cognitivas, e até mesmo nas ciências sociais, bases para confirmar sua crença de que a imitação tem um papel essencial no desenvolvimento, e pode ser uma importante ferramenta na clínica com crianças com déficit de comunicação.

$\mathrm{O}$ terceiro autor a abordar o fenômeno da imitação é Colwin Trevarthen, no artigo intitulado "First things first: infants make good use of the sympathetic rhythm of imitation, without reason or language". Afastando-se da teoria psicanalítica e valendo-se mais de contribuições da psicologia cognitiva, Trevarthen defende a importância da imitação na socialização infantil.

Ele inicia o artigo retomando a dificuldade, tanto da psicanálise quanto da psicologia do desenvolvimento, de compreender a imitação em idades precoces e reconhecer a importância de tais fenômenos para a aprendizagem e o desenvolvimento social. Atribui às pesquisas de Piaget e Skinner, que defendiam a impossibilidade da imitação ocorrer em recém-nascidos o atraso de estudos nesta área. Trevarthen afirma também que, embora a maioria das pesquisas com neonatos revele que, em ambientes laboratoriais, os bebês tendem a não participar dos procedimentos de investigação, dificultando assim a obtenção de resultados confiáveis, esta tendência se inverte quando os bebês são tratados "com respeito", como preconiza Kugiumutzakis (1999). Somente nestas condições eles podem interagir e imitar o pesquisador.

Trevarthen defende uma idéia que podemos relacionar com a hipótese like $m e$ de Meltzoff. $\mathrm{O}$ autor acredita que o recém-nascido já é dotado de um aparelho mental capaz de relacionar seus fenômenos internos àqueles do mundo externo, tendo este aparelho uma importante função no desenvolvimento infantil. Ele afirma ainda que, atualmente, inúmeras pesquisas comprovam a ocorrência da imitação em idades precoces e cita a imitação de expressões faciais, de gestos com a mão, movimentos com os olhos e de sons como imitações encontradas em várias pesquisas. Além da imitação da ação, tais pesquisas defendem que a motivação que subjaz ao ato também é percebida pelo bebê e imitada. A imitação ainda seria utilizada pelo bebê para confirmar sua capacidade de identificar uma determinada pessoa. Tais idéias também se aproximam das teses de Meltzoff.

Uma interessante pesquisa, citada por Trevarthen, foi realizada pela médica húngara Enese Nagy. Após estabelecer um laço com o bebê e o imitar por um 


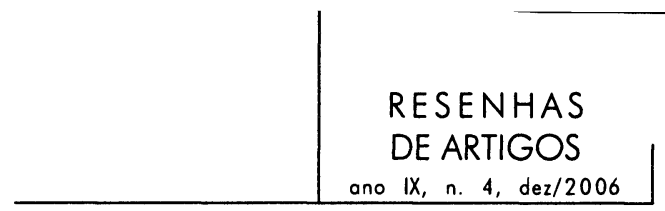

certo período, a pesquisadora interrompeu seus gestos e permaneceu, imóvel, olhando o bebê. Depois de aproximadamente dois minutos o ritmo cardíaco da criança começou a aumentar e logo em seguida ela esboçou algumas imitações, em que seus gestos reproduziam aproximadamente os da pesquisadora. Tal atitude foi interpretada como sendo um fenômeno decorrente de uma capacidade inata do neonato de ter iniciativa, chamada de "provocação" por Nagy. Para Trevarthen, esses comportamentos em idades tão precoces - no caso de Nagy os bebês tinham menos de dois dias de vida - reforçam o inatismo do comportamento interpessoal do bebê e sua capacidade de interagir com adultos, em uma espécie de protoconversação.

Trevarthen afirma que a imitação exerce influência também no desenvolvimento da capacidade de imaginação da criança e na habilidade de intercambiar pontos de vista. Crianças autistas não teriam esta capacidade justamente por apresentarem uma falha em imitar modelos adultos.

Assim como Graham Music, Colwin Trevarthen também cita os estudos sobre neurônios-espelho e defende que a descoberta de que estes são inatos reforça a idéia de que neonatos já são capazes de imitar, pois nascem predispostos a se envolverem em atividades e possuem habilidades necessárias para se relacionarem intersubjetivamente.

Trevarthen conclui dizendo que a teoria psicanalítica criou modelos estáticos para explicar as relações que ele chama de self-outro. Recusa a expressão "relações objetais" para designar os fenômenos interpessoais e defende que as tentativas de criar uma equivalência entre imitação e outros processos psíquicos tais como identificação, internalização e fusões imitativas devem ser evitadas, pois não contribuem para a delimitação desse conceito. Por fim, Trevarthen manifesta sua descrença quanto à possibilidade de se utilizar a noção freudiana de identificação primária para explicar comportamentos imitativos percebidos em idades precoces.

Podemos observar que a revista abriga artigos com algumas posições antagônicas sobre a imitação. Enquanto Trevarthen expressa reservas em relação à aproximação entre identificação primária e imitação, Rhode equipara explicitamente a identificação primária com o tipo de imitação desenvolvimental. Há, no entanto, um consenso entre os autores sobre a importância dos comportamentos imitativos do bebê no seu desenvolvimento emocional. Essa importância já vinha sendo assinalada por trabalhos anteriores, entre os quais está o de Eugenio Gaddini que, com razão, recebe uma atenção especial nesse número do Journal of Child Psychotherapy. Mais do que qualquer outro autor, ele ousou pensar a imitação a partir da metapsicologia freudiana, enfrentando dificuldades, mas abrindo um campo promissor de pesquisa em psicanálise. 


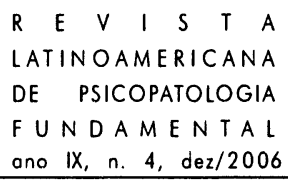

\section{Referências}

Hobson, R.P. \& LEe, A. Comunicação feita na reunião científica da Tavistock Clinic, em 12 de janeiro de 2004.

KugIUMUTZAKIS, G. Neonatal imitation in the intersubjective companion space. In: Braten, S. (org.). Intersubjective Communication and Emotion in Early Ontogeny. Cambridge: Cambridge University Press, 1998.

Genesis and development of early infant mimesis to facial and vocal models. In: Music, G. Surfacing the depths: thoughts and imitatin, resonance and growth. Journal of child psychoterapy, Londres: Routledge. v. 31, n. 1, p. 72-90, abril/20c5.

NADEL, J. \& Butterworth, G. (orgs.). Imitation in Infancy. Cambridge: Cambridge University Press, 1999.

Trevarthen, C. Communication and co-operation in early infance: a description of primary intersubjectivity. In: Bullowa, M. (org.). Before speech. Cambridge: Cambridge University Press, 1979. 